Article

\title{
One-Step and Morphology-Controlled Synthesis of Ni-Co Binary Hydroxide on Nickel Foam for High-Performance Supercapacitors
}

\author{
Xiao Fan, Per Ohlckers* $*$ and Xuyuan Chen * \\ Department of Microsystems, Faculty of Technology, Natural Sciences and Maritime Sciences, \\ University of South-Eastern Norway, Campus Vestfold, Raveien 215, 3184 Borre, Norway; xiao.fan@usn.no \\ * Correspondence: per.ohlckers@usn.no (P.O.); xuyuan.chen@usn.no (X.C.); Tel.: +47-310-09-315 (P.O.); \\ +47-310-09-028 (X.C.)
}

Received: 11 April 2020; Accepted: 29 May 2020; Published: 30 May 2020

\begin{abstract}
Ni-Co binary hydroxide grown on nickel foam was synthesized through a facile one-step process for pseudocapacitive electrode application. The morphology of the fabricated binary hydroxide, evolving from nanosheet to nanowire, was highly controllable by tuning the Ni:Co ratio. In systematical electrochemical measurements, the prepared binary material on nickel foam could be employed as a binder-free working electrode directly. The optimal composition obtained at the Ni:Co ratio of 5:5 in integrated nanosheet/nanowire geometry exhibited high specific capacitances of 2807 and $2222 \mathrm{~F} / \mathrm{g}$ at current densities of 1 and $20 \mathrm{~A} / \mathrm{g}$, equivalent to excellent rate capability. The capacitance loss was $19.8 \%$ after 2000 cycles, demonstrating good long-term cyclic stability. The outstanding supercapacitors behaviors benefited from unique structure and synergistic contributions, indicating the great potential of the obtained binary hydroxide electrode for high-performance energy storage devices.
\end{abstract}

Keywords: Ni-Co binary hydroxide; one-step; controllable morphology; binder-free; supercapacitors; synergistic contributions

\section{Introduction}

The enormously increasing energy requirements and the limited availability of energy sources motivate the development of efficient and safe energy storage devices [1,2]. Supercapacitors, as next-generation high-performance energy storage devices, significantly make up the shortfall of conventional physical capacitors and batteries, and are extremely suitable for superior power density and high charge/discharge rate required applications [3-5], such as electrical vehicles and stop-go driving models [6,7]. In addition, supercapacitors also possess an ultralong service life of up to 10,000 cycles and excellent operating temperature adaptability from $-40^{\circ} \mathrm{C}$ to $+70^{\circ} \mathrm{C}[8,9]$. Accordingly, supercapacitors have sparked extensive interest in recent years. Two types of supercapacitors, divided by energy storage mechanisms, are termed as electric double-layer capacitors and pseudocapacitors, respectively $[10,11]$. Currently, the electric double-layer capacitors, by operating reversible ions' adsorption/desorption to store energy, suffer from lower specific capacitance [12,13], which fails to meet the ever-growing demand. In contrast, pseudocapacitors contribute to higher specific capacitance by reversible faradaic redox reactions $[14,15]$ and have become the research hotspot in supercapacitors fields in past decade.

Among various transition metal oxides/hydroxides for the electrode materials of pseudocapacitors, $\mathrm{Ni}(\mathrm{OH})_{2}$ and $\mathrm{Co}(\mathrm{OH})_{2}$, in virtues of definite redox transitions, superior theoretical specific capacitances (ca. $3750 \mathrm{~F} / \mathrm{g}$ for $\mathrm{Ni}(\mathrm{OH})_{2}$ and ca. $3460 \mathrm{~F} / \mathrm{g}$ for $\mathrm{Co}(\mathrm{OH})_{2}$ ), earth-abundant resources, and environmental friendliness [16,17], have attracted much attentions. For instance, the $\mathrm{Ni}(\mathrm{OH})_{2}$ microspheres, 
synthesized by Du et al., presented the specific capacitance of $1280.9 \mathrm{~F} / \mathrm{g}$ at current density of $0.5 \mathrm{~A} / \mathrm{g}$ [18]. Yin et al. reported the $\mathrm{Co}(\mathrm{OH})_{2}$ nanoflakes delivering $1636 \mathrm{~F} / \mathrm{g}$ at $0.5 \mathrm{~A} / \mathrm{g}$ [19]. However, the achieved specific capacitances by single $\mathrm{Ni}(\mathrm{OH})_{2}$ or $\mathrm{Co}(\mathrm{OH})_{2}$ so far are far lower than the theoretical values, consequently hampering their practical use. To address the issue, novel binary Ni-Co hydroxide was studied and has been shown to outperform the corresponding single hydroxide, owing to unparalleled advantages, such as stronger layered orientation, reduced resistance, increased active sites generated by valence interchange or charge hopping between cations, synergistic redox reaction, moderate redox potential, and decreased redox peak potential difference [20-28]. Unfortunately, even though numerous efforts were devoted, the specific capacitances up to now are still unsatisfied, which are mainly caused by undesirable morphology [29-33] and involved binders [34-38]. Moreover, with respect to high rate capability, cycling stability, good mass loading, and facile method, previous progress to date rarely shows all of these characteristics. For example, the Ni-Co double hydroxide nanosheets prepared by Chen et al. reached ultrahigh $2682 \mathrm{~F} / \mathrm{g}$ at $3 \mathrm{~A} / \mathrm{g}$, but the capacitance loss was more than $35 \%$ at $20 \mathrm{~A} / \mathrm{g}$ [39]. Similarly, the Ni-Co double hydroxides microspheres by Tao and co-workers displayed $2275.5 \mathrm{~F} / \mathrm{g}$ at $1 \mathrm{~A} / \mathrm{g}$, nevertheless the capacitance sharply faded to $1007.8 \mathrm{~F} / \mathrm{g}$ at $25 \mathrm{~A} / \mathrm{g}$ [40]. Besides, Zhang et al. developed flower-like Ni-Co binary hydroxides, in which only $73.8 \%$ capacitance could be maintained after 3000 cycles [41]. Yang and co-workers fabricated Ni-Co hydroxide nanostructures, which demonstrated 1760 and $1468 \mathrm{~F} / \mathrm{g}$ at 1 and $20 \mathrm{~A} / \mathrm{g}$, as well as $87.3 \%$ capacitance retention after 2000 cycles, whereas remarkable criteria were obtained at an exaggerated low mass loading of $0.23 \mathrm{mg} / \mathrm{cm}^{2}$ [42]. In addition, the multi-step and complex routes employed in certain cases further hindered their commercial application. Hence, it is still a challenge to get the utmost out of the binary system for the application of high-performance supercapacitors with promising commercial prospect.

In this paper, we report a novel approach to directly grow Ni-Co binary hydroxides at different $\mathrm{Ni}$ :Co ratios on nickel foam (NF), a substrate with a series of fulfilling features, such as polyporous structure, high surface area, and low resistivity. The optimal electrode has numerous advantages, such as being binder-free, having integrated geometry, moderate redox potential, overlapping redox peaks, and feasible synergistic effect, therefore displaying outstanding overall supercapacitor performances. The simple one-step method further manifests the bright outlook of this study in both research and commercial fields.

\section{Materials and Methods}

\subsection{Preparation of Ni-Co Binary Hydroixde on Nickel Foam}

$\mathrm{Ni}$-Co binary hydroxide on nickel foam was fabricated by a facile one-step solvothermal reaction. Nickel foam $(1 \mathrm{~cm} \times 1 \mathrm{~cm})$ was pretreated with $6 \mathrm{M} \mathrm{HCl}$, deionized water, and ethanol, sequentially. Then, a precursor solution containing the desired molar mixture of $\mathrm{Ni}\left(\mathrm{NO}_{3}\right)_{2} \cdot 6 \mathrm{H}_{2} \mathrm{O}, \mathrm{Co}\left(\mathrm{NO}_{3}\right)_{2} \cdot 6 \mathrm{H}_{2} \mathrm{O}$ (the feeding concentration ratios of $\mathrm{Ni}^{2+}: \mathrm{Co}^{2+}$ were 9:1, 7:3, 5:5, 3:7, and 1:9, respectively, and total molar of cations was $5 \mathrm{mmol}$ ), $2 \mathrm{mmol} \mathrm{NH}_{4} \mathrm{~F}, 6 \mathrm{mmol} \mathrm{CO}\left(\mathrm{NH}_{2}\right)_{2}$, and $50 \mathrm{~mL}$ deionized water was prepared. After vigorous stirring for $10 \mathrm{~min}$, the solution and nickel foam were transferred to a Teflon-lined stainless-steel autoclave and maintained at $120^{\circ} \mathrm{C}$ for $8 \mathrm{~h}$. The final products were rinsed with deionized water after cooling down to room temperature naturally. For convenient clarification, the samples were labeled as $\mathrm{Ni}_{1-\mathrm{x}} \mathrm{Co}_{\mathrm{x}}(\mathrm{OH})_{2}(\mathrm{x}=0.1,0.3,0.5,0.7$, and 0.9$)$. The loading mass on the nickel foam was approximately $1.5 \mathrm{mg} / \mathrm{cm}^{2}$.

\subsection{Material Characterizations}

The surface morphological feature was characterized by a scanning electron microscope (SEM, SU8230, Hitachi, Tokyo, Japan) operated at $10 \mathrm{kV}$. The crystalline structure was investigated via X-ray powder diffraction (XRD, EQUINOX 1000, ThermoFisher, Waltham, America) with $\mathrm{Cu} \mathrm{K} \alpha$ radiation $(\lambda=0.15406 \mathrm{~nm})$. X-ray photoelectron spectroscopy (XPS, ESCALAB 250Xi, ThermoFisher, Waltham, America) under monochromatized $\mathrm{Al} \mathrm{K \alpha}$ excitation was adopted to reveal the chemical status. 


\subsection{Electrochemical Measurements}

The electrochemical performances were evaluated throughout cyclic voltammetry (CV), galvanostatic charge/discharge (GCD), electrochemical impedance spectroscopy (EIS), and long-term cycling on an electrochemical workstation (IM6, Zahner, Kronach, Germany) at room temperature. The configuration, potential window, and electrolyte were set as a three-electrode system, $0-0.5 \mathrm{~V}$ and $2 \mathrm{M} \mathrm{KOH}$, respectively. The $\mathrm{Ni}_{1-\mathrm{x}} \mathrm{Co}_{x}(\mathrm{OH})_{2} / \mathrm{NF}$ served as a working electrode directly while Pt net and $\mathrm{Ag} / \mathrm{AgCl}(3.5 \mathrm{M} \mathrm{KCl})$ were employed as a counter electrode and reference electrode. The measured ranges of scan rate for $\mathrm{CV}$, current density for GCD, and frequency for EIS were 2-50 mV/s, 1-20 A/g and $100 \mathrm{mHz}-100 \mathrm{kHz}$, respectively. The long-term cycling was executed at a constant current density of $20 \mathrm{~A} / \mathrm{g}$ for 2000 cycles.

The specific capacitance, energy density, and power density based on GCD measurement are defined as Equations (1)-(3), respectively [43]:

$$
\begin{gathered}
C=\frac{I t}{m V}, \\
E=\frac{C V^{2}}{7.2}, \\
P=\frac{3.6 E}{t} .
\end{gathered}
$$

where, $C(\mathrm{~F} / \mathrm{g})$ is the specific capacitance, $I(\mathrm{~A})$ is the discharge current, $\Delta t(\mathrm{~s})$ is the discharge time, $m(\mathrm{~g})$ is the mass of active material, $\Delta V(\mathrm{~V})$ is the voltage window, $E(\mathrm{Wh} / \mathrm{kg})$ is the energy density, and $P(\mathrm{~kW} / \mathrm{kg})$ is the power density.

\section{Results}

By controlling the initial ratio of $\mathrm{Ni}$ and $\mathrm{Co}$ in the reactants, the binary material experienced an evident morphological evolution from nanosheet to nanowire, investigated in detail by the SEM, as shown in Figure 1b-f. Figure 1a presents the bare nickel foam with a continuous porous three-dimension (3D) network. At a Ni:Co ratio of 9:1, the nanosheets were observed, as shown in Figure $1 \mathrm{~b}$. Partial nanosheets intersected among each other, displaying an ambiguous nanoflower-like feature. By further increasing content of $\mathrm{Co}$, the morphology of the composite evolved into nanosheet completely, as shown in Figure 1c. Particularly, as more cobalt ions were devoted (intermediate Ni:Co ratio), nanowires appeared and were encapsulated around the nanosheets, as shown in Figure $1 \mathrm{~d}$. The constructed integrated geometry provided a large accessible surface area compared with sole nanosheet morphology. At a greater $\mathrm{Co}$ to $\mathrm{Ni}$ ratio, the nanosheet structures were replaced by uniform nanowires, as shown in Figure 1e. Finally, when Co became dominant (Ni:Co ratio of 1:9), it could be seen that sectional nanowires trended to aggregate, as depicted in Figure 1f. The distinct morphological evolution is ascribed to the competition of $\mathrm{Ni}$ and Co cations for hydroxide radicals [44]. 

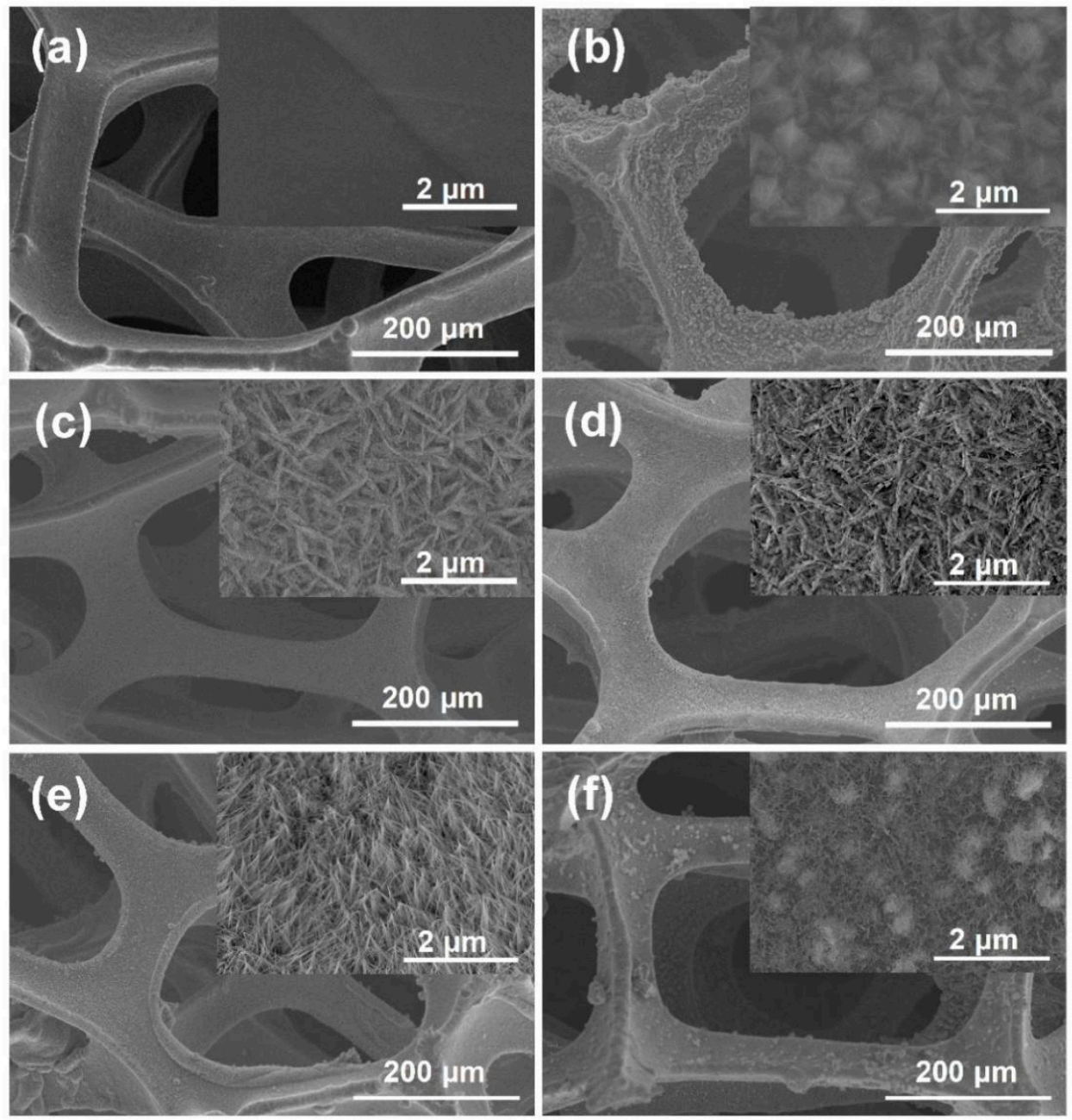

Figure 1. Scanning electron microscope (SEM) images of the samples at different Ni:Co ratios: (a) bare nickel foam; (b) 9:1; (c) 7:3; (d) 5:5; (e) 3:7; (f) 1:9.

The XRD patterns of as-prepared samples under different Ni:Co ratios are shown in Figure 2. The indexed planes of the diffraction peaks at corresponding $2 \theta$ values can be assigned to $\mathrm{Ni}(\mathrm{OH})_{2}$ (JCPDS No. 14-0117) and $\mathrm{Co}(\mathrm{OH})_{2}$ (JCPDS No. 30-0443). The analogous peak positions are believed to be caused by the similar physical and chemical characteristics of $\mathrm{Ni}$ and $\mathrm{Co}$ [45]. When a larger $\mathrm{Co}$ source was applied, the peak signals became weaker and a lacking of partial peaks appeared, which is ascribed to the low crystallinity of the sample [46]. The XPS was carried out to verify the element valence state of the as-synthesized material. The typical XPS survey spectrum of the sample at a Ni:Co ratio of 5:5 is depicted in Figure 3a, where $\mathrm{C}, \mathrm{Ni}, \mathrm{Co}$, and $\mathrm{O}$ were visible. The $\mathrm{C}$ element is due to the air exposure of the sample and can be referenced to calibrate the binding energy $[47,48]$. In the high resolution XPS spectrum of Ni $2 p$, shown in Figure $3 b$, the peaks of Ni $2 p_{3 / 2}$ and Ni $2 p_{1 / 2}$ at binding energies of 855.6 and $873.5 \mathrm{eV}$ (energy separation of $17.9 \mathrm{eV}$ ), as well as two obvious shakeup satellites (denoted as Sat.), indicate the characteristics of $\mathrm{Ni}^{2+}$ [49]. Figure 3c illustrates the core-level XPS spectrum of Co $2 \mathrm{p}$, the peaks at binding energies of 781.4 and $796.9 \mathrm{eV}$ standing for Co $2 \mathrm{p}_{3 / 2}$ and $\mathrm{Co} 2 \mathrm{p}_{1 / 2}$ (energy gap of $15.5 \mathrm{eV}$ ), identify $\mathrm{Co}$ as $\mathrm{Co}^{2+}[50,51]$. The single peak located at $531.1 \mathrm{eV}$ in the $\mathrm{O} 1 \mathrm{~s}$ spectrum, shown in Figure $3 \mathrm{~d}$, is assigned to $\mathrm{OH}-[48,52]$. Hence, it can be concluded that Ni-Co double hydroxides were successfully formed under the present experimental conditions. 


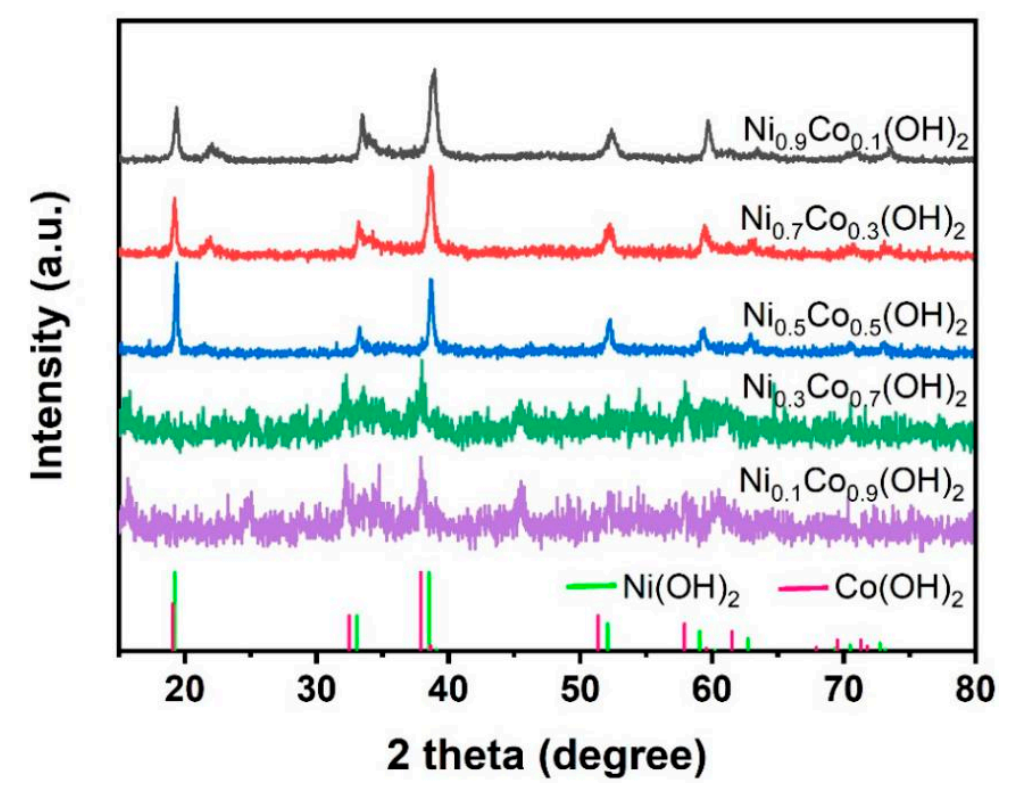

Figure 2. X-ray powder diffraction (XRD) patterns of the $\mathrm{Ni}_{1-\mathrm{x}} \mathrm{Co}_{\mathrm{x}}(\mathrm{OH})_{2}$.
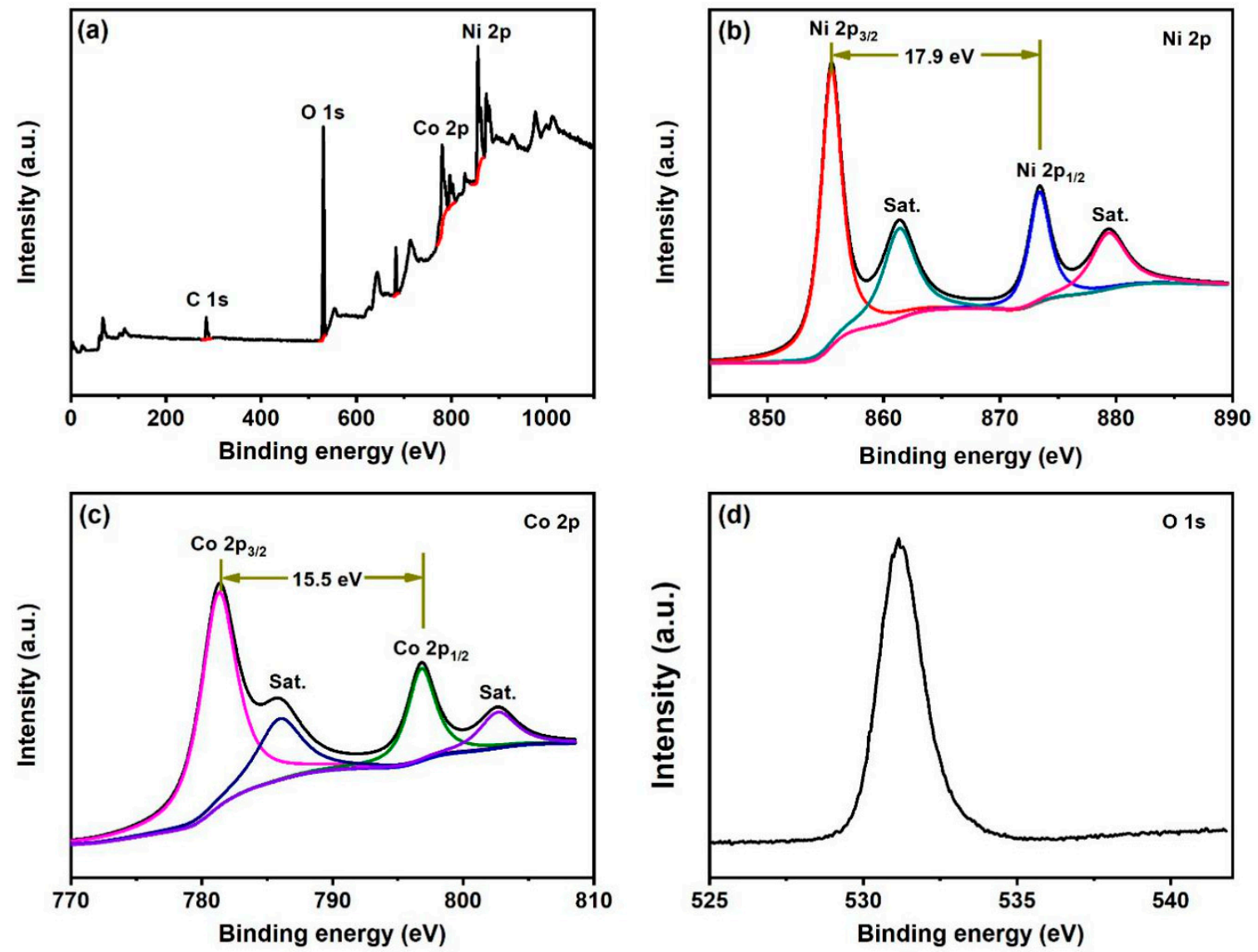

Figure 3. X-ray photoelectron spectroscopy (XPS) spectra of the $\mathrm{Ni}_{0.5} \mathrm{Co}_{0.5}(\mathrm{OH})_{2}$ : (a) survey spectrum; (b) Ni 2p; (c) Co 2p; (d) O 1s.

The CV curves were initially characterized in a potential window of $0-0.5 \mathrm{~V}$ (vs. $\mathrm{Ag} / \mathrm{AgCl}$ ) to evaluate the supercapacitor behavior of the binary materials. The $\mathrm{Ni}_{1-\mathrm{x}} \mathrm{Co}_{\mathbf{x}}(\mathrm{OH})_{2} / \mathrm{NF}$ was directly employed as the binder-free working electrode in a typical three-electrode configuration. The CV curves of the active materials under different $\mathrm{Ni}$ :Co ratios, measured at a scan rate of $2 \mathrm{mV} / \mathrm{s}$, are shown 
in Figure 4a. All CV curves present a distinct pair of peaks, which involves three reversible faradaic redox processes, expressed as Equations (4)-(6) [41]:

$$
\begin{gathered}
\mathrm{Ni}(\mathrm{OH})_{2}+\mathrm{OH}^{-} \leftrightarrow \mathrm{NiOOH}+\mathrm{H}_{2} \mathrm{O}+\mathrm{e}^{-}, \\
\mathrm{Co}(\mathrm{OH})_{2}+\mathrm{OH}^{-} \leftrightarrow \mathrm{CoOOH}+\mathrm{H}_{2} \mathrm{O}+\mathrm{e}^{-}, \\
\mathrm{CoOOH}+\mathrm{OH}^{-} \leftrightarrow \mathrm{CoO}_{2}+\mathrm{H}_{2} \mathrm{O}+\mathrm{e}^{-} .
\end{gathered}
$$

The merged and indistinguishable redox peaks reveal the mixed uniformity of $\mathrm{Ni}$ and $\mathrm{Co}$ in the binary hydroxides [53]. Further, the peaks in anodic sweep move to lower potential when Co content increases, because the potential of Co transition is lower than that of Ni. In other words, the oxidation peak corresponding to $\mathrm{Ni}$ is closer to the voltage window limit [44,54]. The potential window is mainly determined according to the range where effective faradaic reactions occur. At a defined scan rate, the specific capacitance is correlated with the curvilinear integrated area positively based on CV evaluation [43]. Clearly, the maximum area of the CV curve is achieved at a Ni:Co ratio of 5:5. Figure $4 \mathrm{~b}$ displays the $\mathrm{CV}$ curves of the $\mathrm{Ni}_{0.5} \mathrm{Co}_{0.5}(\mathrm{OH})_{2}$ electrode, tested at scan rates of 2, 5, 10,20 , and $50 \mathrm{mV} / \mathrm{s}$. The coupled redox peaks in the CV curves shift positively or negatively with increased scan rates. The classical phenomenon also confirms the pseudocapacitive property of the obtained material [55]. Besides, the relationship of peak currents and the square root of the scan rates delivers a linear response with a steep slope, as described in the inset of Figure $4 \mathrm{~b}$. The distortion of the $\mathrm{CV}$ curves, obtained from 2 to $50 \mathrm{mV} / \mathrm{s}$, is almost negligible. The characteristics above illustrate the excellent reversibility and rapid response of the $\mathrm{Ni}_{0.5} \mathrm{Co}_{0.5}(\mathrm{OH})_{2}$ electrode, promisingly leading to a desirable rate capability [56].
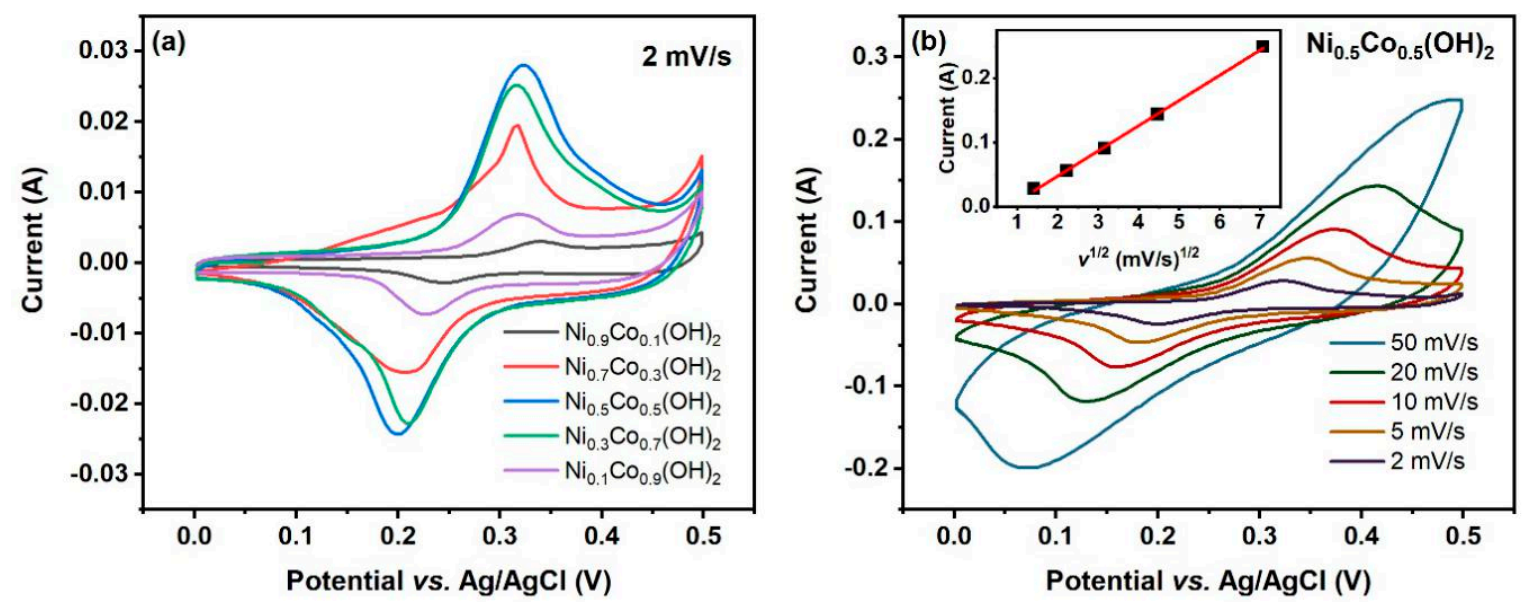

Figure 4. (a) Cyclic voltammetry $(\mathrm{CV})$ curves of the $\mathrm{Ni}_{1-\mathrm{x}} \mathrm{Co}_{\mathrm{x}}(\mathrm{OH})_{2}$ electrodes at scan rate of $2 \mathrm{mV} / \mathrm{s}$. (b) CV curves of the $\mathrm{Ni}_{0.5} \mathrm{Co}_{0.5}(\mathrm{OH})_{2}$ electrode at scan rates from 2 to $50 \mathrm{mV} / \mathrm{s}$.

The GCD tests through the same three-electrode system were conducted on the binary hydroxide electrodes to demonstrate the electrochemical properties further. The GCD curves of the $\mathrm{Ni}_{1-\mathrm{x}} \mathrm{Co}_{\mathrm{x}}(\mathrm{OH})_{2}$ electrodes, measured at current densities of $1,2,5,10$, and $20 \mathrm{~A} / \mathrm{g}$ in a potential range of $0-0.5 \mathrm{~V}$ (vs. $\mathrm{Ag} / \mathrm{AgCl}$ ), are shown in Figure $5 \mathrm{a}-\mathrm{e}$, respectively. As expected, all non-linear curves deliver well-defined plateaus, arising from redox reactions, also suggesting the pseudocapacitive features of the synthesized materials [54]. What is more, the plateaus are still dimly visible, even at a current density of $20 \mathrm{~A} / \mathrm{g}$, which implies a slight decay of the specific capacitance at high current density could possibly be reached. In GCD measurements, the specific capacitance is proportional to the discharge time [43]. Figure $5 \mathrm{f}$ intuitively depicts that the proposed $\mathrm{Ni}_{0.5} \mathrm{Co}_{0.5}(\mathrm{OH})_{2}$ electrode takes the longest time to complete one discharge process, which is in good agreement with the CV results exhibited in Figure 4a. 

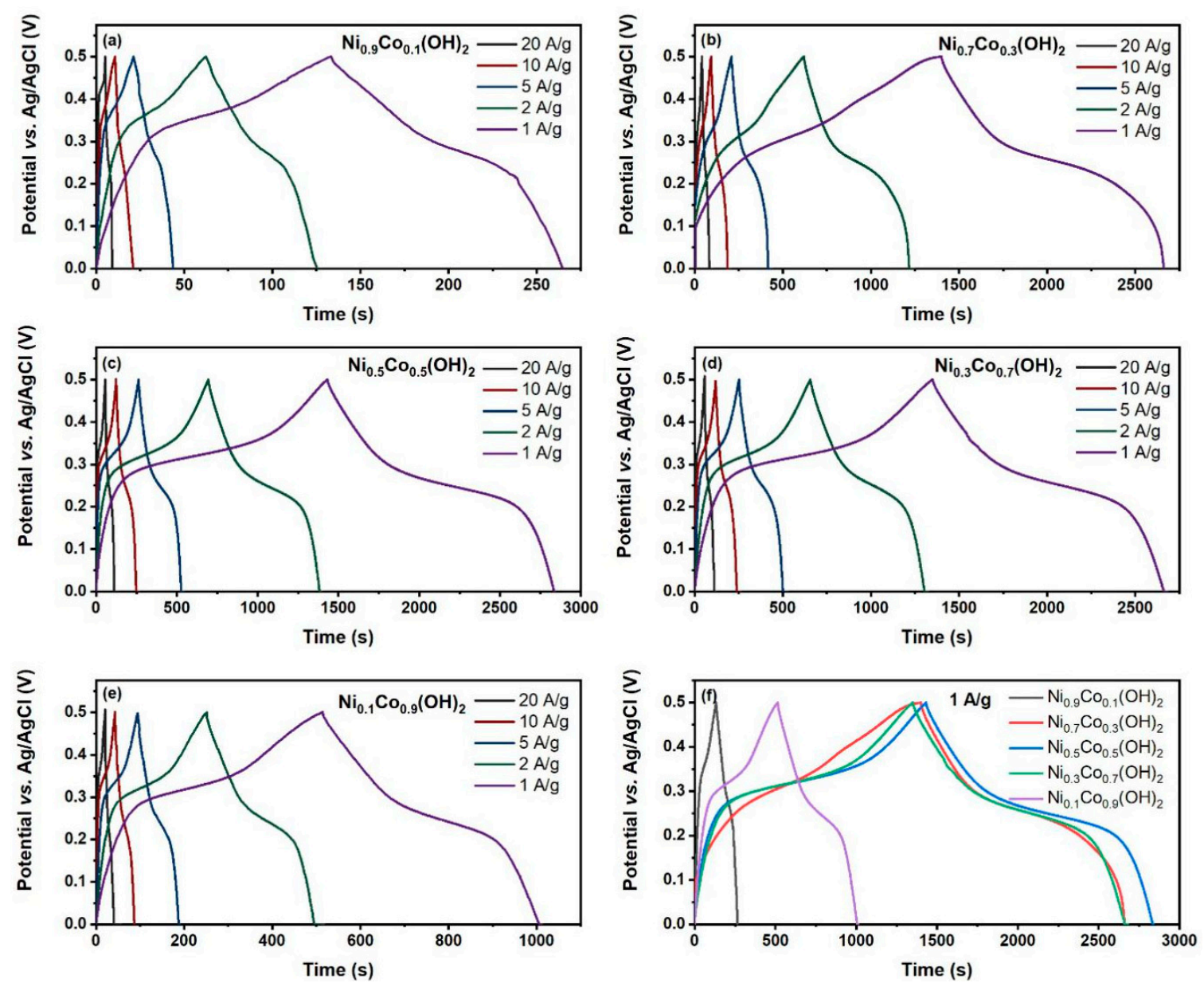

Figure 5. Galvanostatic charge/discharge (GCD) curves at current densities from 1 to $20 \mathrm{~A} / \mathrm{g}$ : (a) $\mathrm{Ni}_{0.9} \mathrm{Co}_{0.1}(\mathrm{OH})_{2} ;$ (b) $\mathrm{Ni}_{0.7} \mathrm{Co}_{0.3}(\mathrm{OH})_{2} ;$ (c) $\mathrm{Ni}_{0.5} \mathrm{Co}_{0.5}(\mathrm{OH})_{2} ;$ (d) $\mathrm{Ni}_{0.3} \mathrm{Co}_{0.7}(\mathrm{OH})_{2} ;(\mathbf{e}) \mathrm{Ni}_{0.1} \mathrm{Co}_{0.9}(\mathrm{OH})_{2}$;

(f) GCD curves of the $\mathrm{Ni}_{1-\mathrm{x}} \mathrm{Co}_{\mathrm{x}}(\mathrm{OH})_{2}$ electrodes at current density of $1 \mathrm{~A} / \mathrm{g}$.

The specific capacitances based on the GCD tests were determined according to Equation (1). The calculated values as a function of current densities for all as-prepared electrodes are plotted in Figure 6a. All of the function graphs show a similar attenuation tendency, namely, the produced specific capacitances decrease accompanied by the boost of current densities. Admittedly, the unsatisfying fade is inevitable, owing to the limited diffusion of electrolyte ions (OH- in this work). Briefly, in comparison with low current density, the time for $\mathrm{OH}$ - transfer is inadequate at high current density, leading to the fact that involved active material in redox reactions is also insufficient [57]. The specific capacitance becomes greater with the content of $\mathrm{Co}$ in the binary hydroxide until the intermediate ratio. Beyond this ratio, a decrease in capacitive performance appears. This phenomenon is consistent with previous literature [54,58-61]. The $\mathrm{Ni}_{0.5} \mathrm{Co}_{0.5}(\mathrm{OH})_{2}$ electrode delivers high specific capacitances of 2807,2751 , 2622,2444 , and $2222 \mathrm{~F} / \mathrm{g}$ at current densities of 1, 2, 5, 10 and $20 \mathrm{~A} / \mathrm{g}$, which is attributed to the integrated nanosheet/nanowire geometry and broadened redox behavior at a Ni:Co ratio of 5:5. The specific capacitance, reached as an important parameter for supercapacitors, manifests in the great application prospect of the obtained $\mathrm{Ni}_{0.5} \mathrm{Co}_{0.5}(\mathrm{OH})_{2}$ electrode. Among five composites, the $\mathrm{Ni}_{0.9} \mathrm{Co}_{0.1}(\mathrm{OH})_{2}$ and $\mathrm{Ni}_{0.1} \mathrm{Co}_{0.9}(\mathrm{OH})_{2}$ electrodes express large differences in specific capacitances compared with the other three samples. The poor ability under the same measured conditions is mainly due to the aggregation of material, which deteriorates the accessibility of electrolyte ions in electroactive material. Furthermore, the $\mathrm{Ni}_{0.5} \mathrm{Co}_{0.5}(\mathrm{OH})_{2}$ electrode still maintains a specific capacitance of $79.2 \%$, even when the current density increases 20 -times more than the initial value, representing an excellent rate capability. What is noteworthy is that the $\mathrm{Ni}_{0.3} \mathrm{Co}_{0.7}(\mathrm{OH})_{2}$ electrode offers a slightly higher rate capability of $82 \%$ ( 2624 and 
$2151 \mathrm{~F} / \mathrm{g}$ at 1 and $20 \mathrm{~A} / \mathrm{g}$ ) than that of the $\mathrm{Ni}_{0.5} \mathrm{Co}_{0.5}(\mathrm{OH})_{2}$ sample, which highlights the advantage of nanowire morphology as a one-dimension (1D) geometry, which can better guarantee effective ion diffusion and electron transportation at high current density [44,62]. Based on Equations (2) and (3), the Ragone plots of the samples were obtained to further illustrate the electrochemical properties, as exhibited in Figure $6 \mathrm{~b}$. The $\mathrm{Ni}_{0.5} \mathrm{Co}_{0.5}(\mathrm{OH})_{2}$ sample shows energy densities of 97.5, 95.5, 91, 84.9 and $77.2 \mathrm{Wh} / \mathrm{kg}$ at power densities of $0.25,0.5,1.25,2.5$ and $5 \mathrm{~kW} / \mathrm{kg}$, respectively.
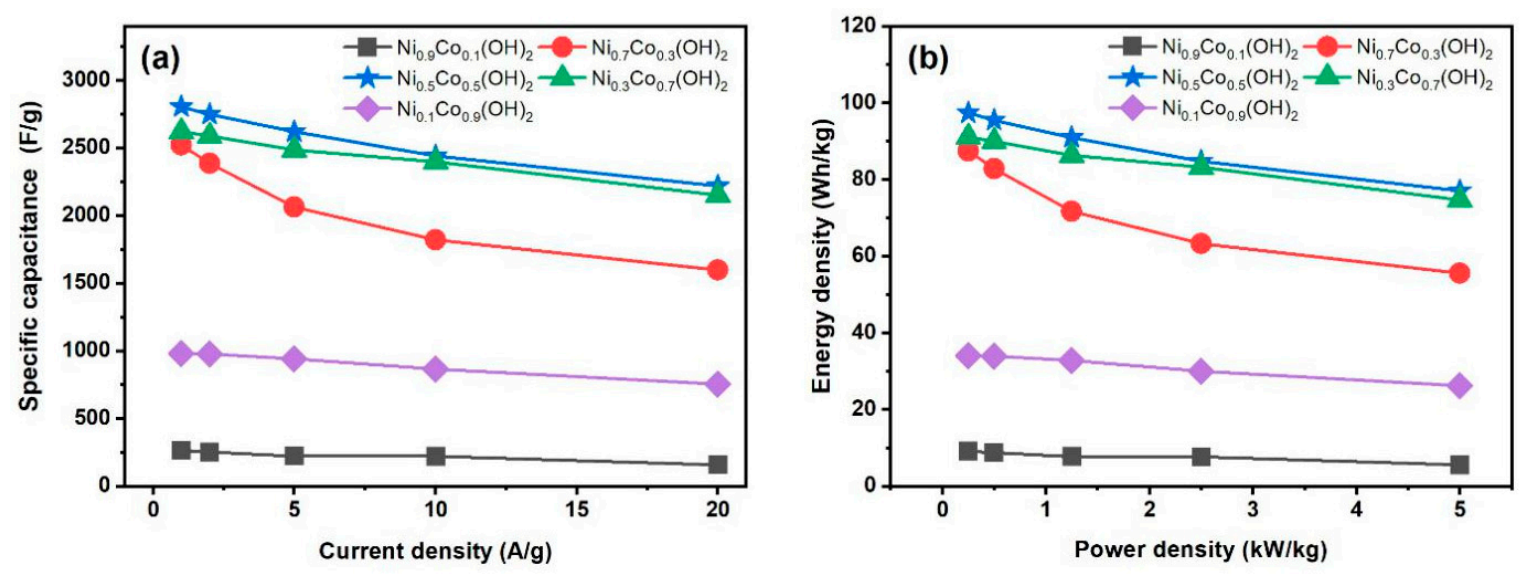

Figure 6. (a) Specific capacitances as a function of current densities and (b) Ragone plots of the $\mathrm{Ni}_{1-\mathrm{x}} \mathrm{Co}_{\mathrm{x}}(\mathrm{OH})_{2}$ samples.

The EIS studies over the frequency range of $100 \mathrm{mHz}$ to $100 \mathrm{kHz}$ in $2 \mathrm{M} \mathrm{KOH}$ were carried out on $\mathrm{Ni}_{0.7} \mathrm{Co}_{0.3}(\mathrm{OH})_{2}, \mathrm{Ni}_{0.5} \mathrm{Co}_{0.5}(\mathrm{OH})_{2}$, and $\mathrm{Ni}_{0.3} \mathrm{Co}_{0.7}(\mathrm{OH})_{2}$ as optimized electrodes. Figure 7a records the typical Nyquist plots. Generally, the intrinsic resistances (electrolyte and material) and contact resistances (electrolyte/material and material/current collector) are summarized as $R_{\mathrm{S}}$, which is valued from the intersection of the EIS plot and real axis. Figure $7 \mathrm{~b}$ illustrates the high frequency in an enlarged view, in which the semicircle corresponds to the charge transfer resistance $\left(R_{\mathrm{ct}}\right)$. The straight line at the low frequency portion represents the ion diffusion in the electrolyte, arising in a Warburg element $(W)[61,63,64]$. The $\mathrm{Ni}_{0.3} \mathrm{Co}_{0.7}(\mathrm{OH})_{2}$ electrode delivers the smallest diameter (expressing lowest $R_{\mathrm{ct}}$ ) and largest slop (suggesting fastest ion diffusion), which is consistent with its outstanding rate performance. The highest specific capacitance produced by the $\mathrm{Ni}_{0.5} \mathrm{Co}_{0.5}(\mathrm{OH})_{2}$ electrode is due to: (1) the union of $\mathrm{Ni}$ and $\mathrm{Co}$ at ratio of 5:5 generating most electroactive sites from the feasible interaction of the valence state electron [54]; (2) the $R_{\mathrm{s}}$ value of the $\mathrm{Ni}_{0.5} \mathrm{Co}_{0.5}(\mathrm{OH})_{2}$ electrode being lower than the others. Overall, the EIS spectra well coincide with the aforementioned CV and GCD results. Figure $7 \mathrm{c}$ presents the fitting equivalent circuit, where $C_{\mathrm{dl}}$ and $C_{\mathrm{ps}}$ account for double-layer capacitance and pseudocapacitance, respectively.

The long-term electrochemical stability was assessed via repetitive GCD tests at a constant current density of $20 \mathrm{~A} / \mathrm{g}$. Figure 8 displays the capacitance retentions and coulombic efficiencies of the $\mathrm{Ni}_{0.5} \mathrm{Co}_{0.5}(\mathrm{OH})_{2}$ electrode as a function of the cycle numbers (the inset depicts the GCD curves of the last 10 cycles). The coulombic efficiency is calculated based on Equation (7) [63]:

$$
\eta=\frac{t_{d}}{t_{c}}
$$

where, $\eta(\%)$ is the coulombic efficiency, $t_{\mathrm{d}}(\mathrm{s})$ is the discharge time, and $t_{\mathrm{c}}(\mathrm{s})$ is the charge time. As recorded in Figure 8, the deduced capacitance retentions gradually decreased at first, and after approximately 1000 cycles remained nearly constant. Impressively, even after 2000 cycles, the $\mathrm{Ni0}{ }_{5} \mathrm{Co}_{0.5}(\mathrm{OH})_{2}$ electrode still reached $80.2 \%$ of its initial specific capacitance and its high coulombic efficiency exceeded $90 \%$. The capacitance loss after long-term cycling is inevitable, which is likely attributed to several reasons, (e.g., the presence of irreversible redox reactions, damage to the electrode, 
or impurities in the electrolyte) [65]. The remarkable durability performance of the $\mathrm{Ni}_{0.5} \mathrm{Co}_{0.5}(\mathrm{OH})_{2}$ electrode is pivotal for potential commercial application. In contrast, the cycling stability of the $\mathrm{Ni}_{0.3} \mathrm{Co}_{0.7}(\mathrm{OH})_{2}$ electrode is poor (capacitance retention of $62.1 \%$ after 2000 cycles), possibly since partial nanowires were not attached to the nickel foam tightly enough, giving rise to low material utilization for capacitance.
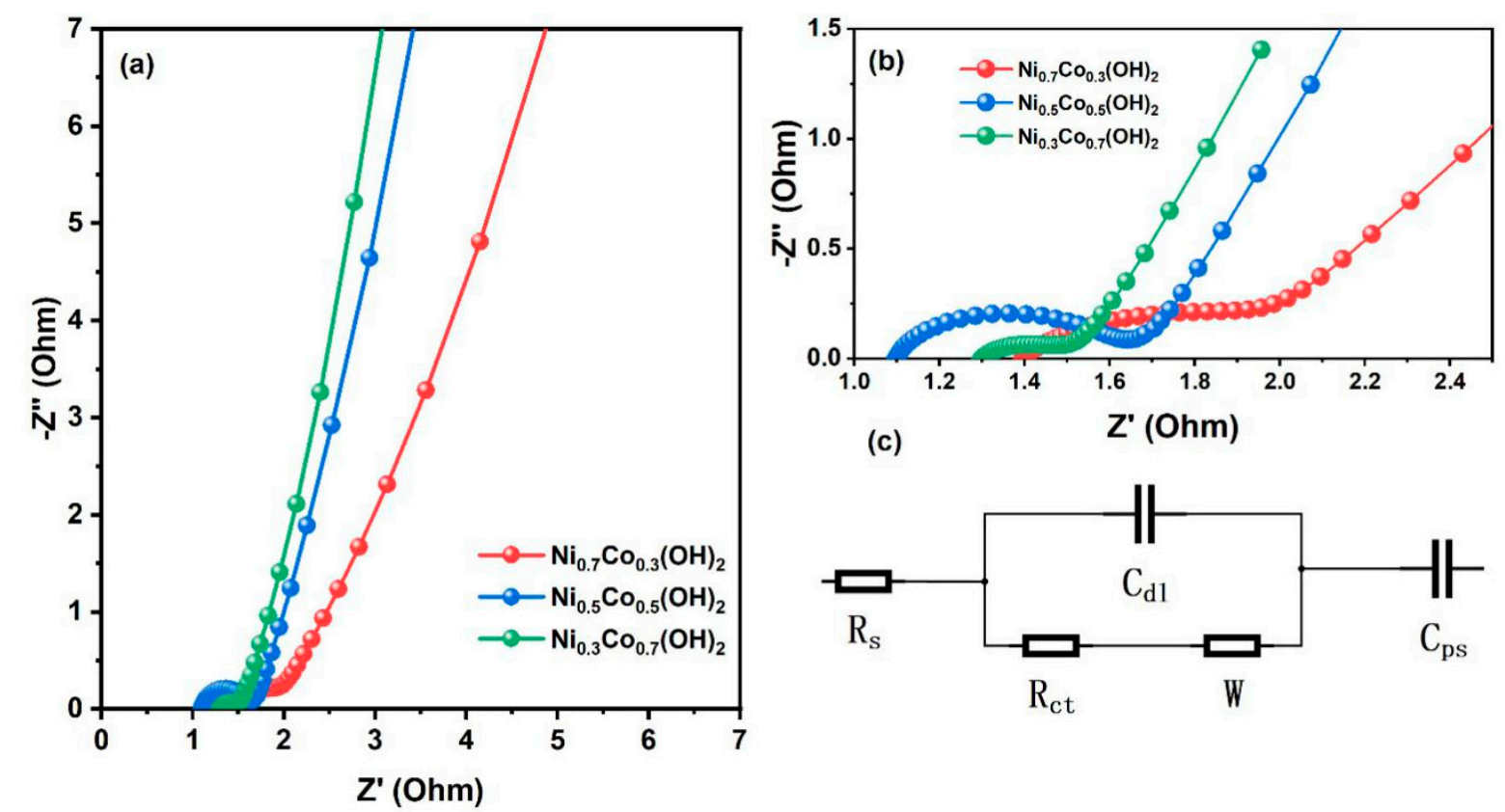

Figure 7. (a) Electrochemical impedance spectroscopy (EIS) plots of the $\mathrm{Ni}_{0.7} \mathrm{Co}_{0.3}(\mathrm{OH})_{2}, \mathrm{Ni}_{0.5} \mathrm{Co}_{0.5}(\mathrm{OH})_{2}$, and $\mathrm{Ni}_{0.3} \mathrm{Co}_{0.7}(\mathrm{OH})_{2}$ electrodes. (b) Enlarged view of the high frequency region. (c) Fitting equivalent circuit.

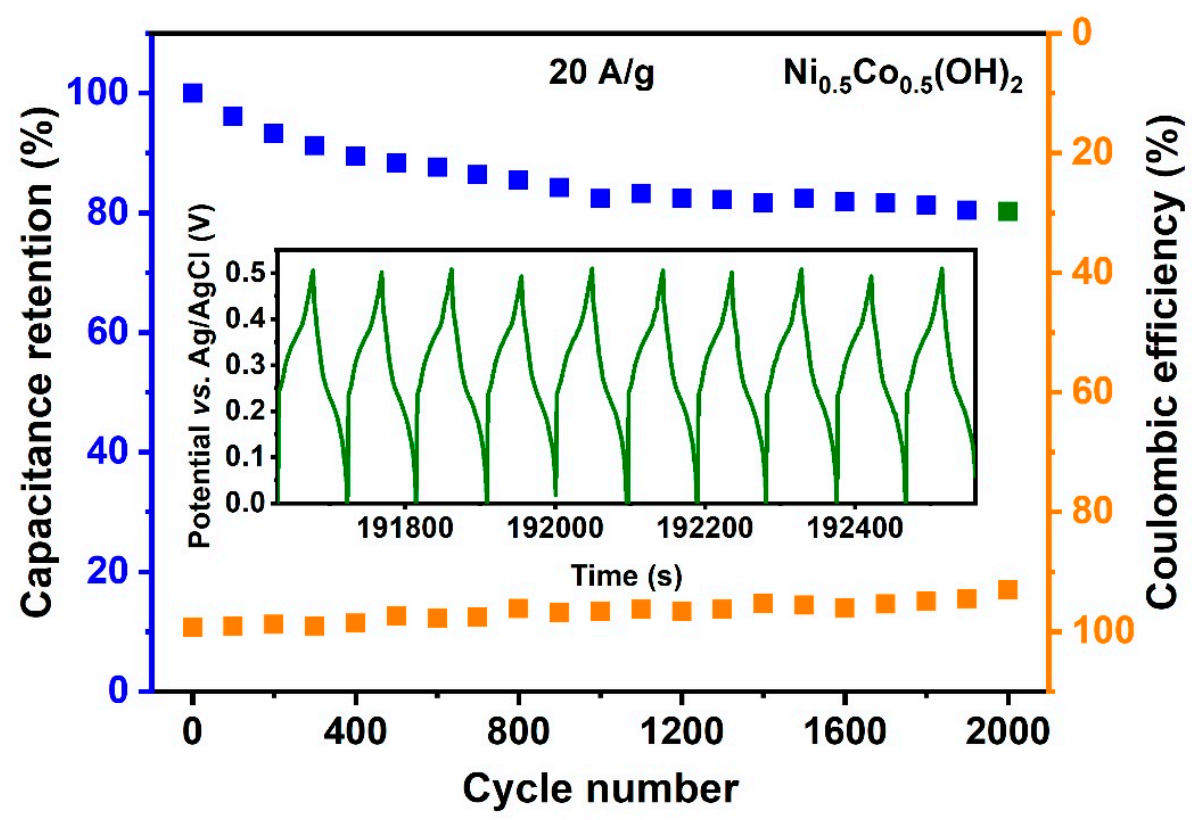

Figure 8. Cycling performance and coulombic efficiency of the $\mathrm{Ni}_{0.5} \mathrm{Co}_{0.5}(\mathrm{OH})_{2}$ electrode.

\section{Discussion}

To summarize, the $\mathrm{Ni}_{1-\mathrm{x}} \mathrm{Co}_{\mathrm{x}}(\mathrm{OH})_{2}$ electrode possessed the best overall supercapacitor performance when $x$ equals 0.5 was investigated in terms of specific capacitance, rate capability, and cycling stability. These superior behaviors are attributed to the common advantages of the binary system and the unique 
merits of $\mathrm{Ni}_{0.5} \mathrm{Co}_{0.5}(\mathrm{OH})_{2}$. Firstly, the synthesized material is grown directly onto the surface of nickel foam rather than by virtue of a binder, affording an intimate electric contact. Secondly, the oxidation peak of Ni moves towards comparatively lower potential by introducing $\mathrm{Co}$, which avoids possible solvent oxidation [44]. Thirdly, the overlapping redox peaks broaden the redox features and improve redox response. In addition, the integrated nanosheet/nanowire architecture of $\mathrm{Ni}_{0.5} \mathrm{Co}_{0.5}(\mathrm{OH})_{2}$ increases the active sites for redox reaction and pathways for electron transportation. On the other hand, the $\mathrm{Ni}_{0.5} \mathrm{Co}_{0.5}(\mathrm{OH})_{2}$ electrode delivers the lowest intrinsic and contact resistances (i.e., $R_{\mathrm{s}}$ ). Moreover, the $\mathrm{Ni}_{0.5} \mathrm{Co}_{0.5}(\mathrm{OH})_{2}$ possibly possesses the most electroactive sites generated by valence interchange or charge hopping between cations [58]. The specific capacitance of the $\mathrm{Ni}_{0.5} \mathrm{Co}_{0.5}(\mathrm{OH})_{2}$ electrode is even higher than those of some hybrid materials [66-68]. Apart from remarkable specific capacitance, the high rate capability of $79.2 \%$ at current density of $20 \mathrm{~A} / \mathrm{g}$ and the slight capacitance decay of $19.8 \%$ after 2000 cycles are also satisfied.

\section{Conclusions}

In summary, the Ni-Co binary hydroxide system was fabricated by a facile one-step hydrothermal reaction. By tailoring the cation ratio in preparation, the morphology of the binary system evolved from nanosheet to nanowire straightforwardly, as a consequence, giving rise to different supercapacitor behaviors. The optimal electrode achieved at a Ni:Co ratio of 5:5 exhibited a prominent specific capacitance of $2807 \mathrm{~F} / \mathrm{g}$ at a current density of $1 \mathrm{~A} / \mathrm{g}$ (based on active material) as well as outstanding rate $(79.2 \%$ capacitance retention at $20 \mathrm{~A} / \mathrm{g})$ and cycling $(80.2 \%$ capacitance retention after 2000 cycles) performances. The remarkable criteria and the environmentally friendly method manifest great prospects of the obtained $\mathrm{Ni}_{0.5} \mathrm{Co}_{0.5}(\mathrm{OH})_{2}$ electrode for commercial application in high-performance supercapacitors. Furthermore, this novel approach is also promisingly adopted to develop other binary systems using different electrochemically active metal hydroxides for wide applications not only in supercapacitors, but also in catalysts, sensors, and so forth.

Author Contributions: Conceptualization, X.C. and P.O.; methodology, X.F., P.O., and X.C.; software, X.F.; validation, X.F., P.O., and X.C.; formal analysis, X.F.; investigation, X.C. and P.O.; resources, X.C. and P.O.; data curation, X.F., P.O., and X.C.; writing-original draft preparation, X.F.; writing-review and editing, X.C. and P.O.; visualization, X.F., P.O., and X.C.; supervision, X.C. and P.O.; project administration, X.C. and P.O.; funding acquisition, X.C. All authors have read and agreed to the published version of the manuscript.

Funding: This research was funded by the Research Council of Norway (RCN, grant number 221860/F60) and the Norwegian Micro- and Nano-Fabrication Facility (NorFab, project number 245963). Xiao Fan was financially supported by the China Scholarship Council (CSC, grant number 201506930018).

Acknowledgments: The authors gratefully acknowledge lab engineers Zekija Ramic, Thomas Martinsen, Tayyib Muhammad, Anh Tuan Thai Nguyen, and Birgitte Kasin Hønsvall for their kind help associated with this work. The authors also specially thank Einar Halvorsen, Pai Lu, and Yongjiao Sun for their critical suggestions.

Conflicts of Interest: The authors declare no conflict of interest.

\section{References}

1. Wang, L.; Han, Y.; Feng, X.; Zhou, J.; Qi, P.; Wang, B. Metal-organic frameworks for energy storage: Batteries and supercapacitors. Coord. Chem. Rev. 2016, 307, 361-381. [CrossRef]

2. González, A.; Goikolea, E.; Barrena, J.A.; Mysyk, R. Review on supercapacitors: Technologies and materials. Renew. Sustain. Energy Rev. 2016, 58, 1189-1206. [CrossRef]

3. Dubal, D.P.; Ayyad, O.; Ruiz, V.; Gomez-Romero, P. Hybrid energy storage: The merging of battery and supercapacitor chemistries. Chem. Soc. Rev. 2015, 44, 1777-1790. [CrossRef] [PubMed]

4. Zhang, L.; Hu, X.; Wang, Z.; Sun, F.; Dorrell, D.G. A review of supercapacitor modeling, estimation, and applications: A control/management perspective. Renew. Sustain. Energy Rev. 2018, 81, 1868-1878. [CrossRef]

5. Conway, B.E. Transition from "supercapacitor" to "battery" behavior in electrochemical energy storage. J. Electrochem. Soc. 1991, 138, 1539. [CrossRef] 
6. Castaings, A.; Lhomme, W.; Trigui, R.; Bouscayrol, A. Comparison of energy management strategies of a battery/supercapacitors system for electric vehicle under real-time constraints. Appl. Energy 2016, 163, 190-200. [CrossRef]

7. Faggioli, E.; Rena, P.; Danel, V.; Andrieu, X.; Mallant, R.; Kahlen, H. Supercapacitors for the energy management of electric vehicles. J. Power Sources 1999, 84, 261-269. [CrossRef]

8. Tang, Z.; Tang, C.H.; Gong, H. A high energy density asymmetric supercapacitor from nano-architectured $\mathrm{Ni}(\mathrm{OH})_{2} /$ Carbon nanotube electrodes. Adv. Funct. Mater. 2012, 22, 1272-1278. [CrossRef]

9. Kötz, R.; Hahn, M.; Gallay, R. Temperature behavior and impedance fundamentals of supercapacitors. J. Power Sources 2006, 154, 550-555. [CrossRef]

10. Kang, J.; Zhang, S.; Zhang, Z. Three-dimensional binder-free nanoarchitectures for advanced pseudocapacitors. Adv. Mater. 2017, 29, 1700515. [CrossRef]

11. Salanne, M.; Rotenberg, B.; Naoi, K.; Kaneko, K.; Taberna, P.L.; Grey, C.P.; Dunn, B.; Simon, P. Efficient storage mechanisms for building better supercapacitors. Nat. Energy 2016, 1, 1-10. [CrossRef]

12. Ke, Q.; Wang, J. Graphene-based materials for supercapacitor electrodes-A review. J. Mater. 2016, 2, 37-54. [CrossRef]

13. Borenstein, A.; Hanna, O.; Attias, R.; Luski, S.; Brousse, T.; Aurbach, D. Carbon-based composite materials for supercapacitor electrodes: A review. J. Mater. Chem. A 2017, 5, 12653-12672. [CrossRef]

14. Lu, Q.; Chen, J.G.; Xiao, J.Q. Nanostructured electrodes for high-performance pseudocapacitors. Angew. Chem. Int. Ed. 2013, 52, 1882-1889. [CrossRef] [PubMed]

15. Wang, C.; Xu, J.; Yuen, M.F.; Zhang, J.; Li, Y.; Chen, X.; Zhang, W. Hierarchical composite electrodes of nickel oxide nanoflake 3D graphene for high-performance pseudocapacitors. Adv. Funct. Mater. 2014, 24, 6372-6380. [CrossRef]

16. Chen, X.; Zhang, F.; Yang, Z.; Huang, S. One-pot hydrothermal synthesis of reduced graphene oxide/carbon nanotube/ $\alpha-\mathrm{Ni}(\mathrm{OH})_{2}$ composites for high performance electrochemical supercapacitor. J. Power Sources 2013, 243, 555-561. [CrossRef]

17. Zhao, C.; Wang, X.; Wang, S.; Wang, Y.; Zhao, Y.; Zheng, W. Synthesis of $\mathrm{Co}(\mathrm{OH})_{2} /$ graphene/Ni foam nano-electrodes with excellent pseudocapacitive behavior and high cycling stability for supercapacitors. Int. J. Hydrog. Energy 2012, 37, 11846-11852. [CrossRef]

18. Du, H.; Wang, Y.; Yuan, H.; Jiao, L. Facile synthesis and high capacitive performance of 3D hierarchical $\mathrm{Ni}(\mathrm{OH})_{2}$ microspheres. Electrochim. Acta 2016, 196, 84-91. [CrossRef]

19. Yin, T.; Zhang, W.; Yin, Y.; Yan, Y.; Zhan, K.; Yang, J.; Zhao, B. $\mathrm{Co}(\mathrm{OH})_{2}$ nanoflakes grown on 3D graphene foam as a binder-free hybrid electrode for high-performance supercapacitors. J. Mater. Sci. Mater. Electron. 2017, 28, 7884-7891. [CrossRef]

20. Nguyen, T.; Boudard, M.; Carmezim, M.J.; Montemor, M.F. $\mathrm{Ni}_{\mathrm{x}} \mathrm{Co}_{1-\mathrm{x}}(\mathrm{OH})_{2}$ nanosheets on carbon nanofoam paper as high areal capacity electrodes for hybrid supercapacitors. Energy 2017, 126, 208-216. [CrossRef]

21. Xiong, G.; He, P.; Wang, D.; Zhang, Q.; Chen, T.; Fisher, T.S. Hierarchical Ni-Co Hydroxide Petals on Mechanically Robust Graphene Petal Foam for High-Energy Asymmetric Supercapacitors. Adv. Funct. Mater. 2016, 26, 5460-5470. [CrossRef]

22. Liu, X.; Ma, R.; Bando, Y.; Sasaki, T. A general strategy to layered transition-metal hydroxide nanocones: Tuning the composition for high electrochemical performance. Adv. Mater. 2012, 24, 2148-2153. [CrossRef] [PubMed]

23. Armstrong, R.D.; Charles, E.A. Some effects of cobalt hydroxide upon the electrochemical behaviour of nickel hydroxide electrodes. J. Power Sources 1989, 25, 89-97. [CrossRef]

24. Nguyen, T.; Boudard, M.; Carmezim, M.J.; Montemor, M.F. Layered Ni $(\mathrm{OH})_{2}-\mathrm{Co}(\mathrm{OH})_{2}$ films prepared by electrodeposition as charge storage electrodes for hybrid supercapacitors. Sci. Rep. 2017, 7, 1-10. [CrossRef]

25. Chen, J.C.; Hsu, C.T.; Hu, C.C. Superior capacitive performances of binary nickel-cobalt hydroxide nanonetwork prepared by cathodic deposition. J. Power Sources 2014, 253, 205-213. [CrossRef]

26. Wang, C.; Zhang, X.; Xu, Z.; Sun, X.; Ma, Y. Ethylene glycol intercalated cobalt/nickel layered double hydroxide nanosheet assemblies with ultrahigh specific capacitance: Structural design and green synthesis for advanced electrochemical storage. ACS Appl. Mater. Interfaces 2015, 7, 19601-19610. [CrossRef]

27. Hamal, E.K.; Toroker, M.C. The Effect of Fe and Co Additions on the Efficiency of NiOOH Catalyst Under Strain. ChemCatChem 2020, 12, 2801-2806. [CrossRef] 
28. Hwang, M.; Kang, J.; Seong, K.D.; Kim, D.K.; Jin, X.; Antink, W.H.; Lee, C.; Piao, Y. Ni-Co hydroxide nanoneedles embedded in graphene hydrogel as a binder-free electrode for high-performance asymmetric supercapacitor. Electrochim. Acta 2018, 270, 156-164. [CrossRef]

29. Salunkhe, R.R.; Jang, K.; Lee, S.W.; Ahn, H. Aligned nickel-cobalt hydroxide nanorod arrays for electrochemical pseudocapacitor applications. RSC Adv. 2012, 2, 3190-3193. [CrossRef]

30. Yan, T.; Li, R.; Li, Z. Nickel-cobalt layered double hydroxide ultrathin nanoflakes decorated on graphene sheets with a 3D nanonetwork structure as supercapacitive materials. Mater. Res. Bull. 2014, 51, 97-104. [CrossRef]

31. Zheng, X.; Gu, Z.; Hu, Q.; Geng, B.; Zhang, X. Ultrathin porous nickel-cobalt hydroxide nanosheets for high-performance supercapacitor electrodes. RSC Adv. 2015, 5, 17007-17013. [CrossRef]

32. Li, M.; Ma, K.Y.; Cheng, J.P.; Lv, D.; Zhang, X.B. Nickel-cobalt hydroxide nanoflakes conformal coating on carbon nanotubes as a supercapacitive material with high-rate capability. J. Power Sources 2015, 286, 438-444. [CrossRef]

33. Li, H.; Musharavati, F.; Zalenezhad, E.; Chen, X.; Hui, K.N.; Hui, K.S. Electrodeposited NiCo layered double hydroxides on titanium carbide as a binder-free electrode for supercapacitors. Electrochim. Acta 2018, 261, 178-187. [CrossRef]

34. Li, J.; Wei, M.; Chu, W.; Wang, N. High-stable $\alpha$-phase NiCo double hydroxide microspheres via microwave synthesis for supercapacitor electrode materials. Chem. Eng. J. 2017, 316, 277-287. [CrossRef]

35. Tao, Y.; Ruiyi, L.; Zaijun, L.; Junkang, L.; Guangli, W.; Zhiquo, G. A free template strategy for the fabrication of nickel/cobalt double hydroxide microspheres with tunable nanostructure and morphology for high performance supercapacitors. RSC Adv. 2013, 3, 19416-19422. [CrossRef]

36. He, S.; Li, Z.; Wang, J.; Wen, P.; Gao, J.; Ma, L.; Yang, Z.; Yang, S. MOF-derived $\mathrm{Ni}_{\mathrm{x}} \mathrm{Co}_{1-\mathrm{x}}(\mathrm{OH})_{2}$ composite microspheres for high-performance supercapacitors. RSC Adv. 2016, 6, 49478-49486. [CrossRef]

37. Gou, J.; Xie, S.; Liu, Y.; Liu, C. Flower-like nickel-cobalt hydroxides converted from phosphites for high rate performance hybrid supercapacitor electrode materials. Electrochim. Acta 2016, 210, 915-924. [CrossRef]

38. Tao, Y.; Ruiyi, L.; Tingting, Y.; Zaijun, L. Nickel/cobalt layered double hydroxide hollow microspheres with hydrangea-like morphology for high-performance supercapacitors. Electrochim. Acta 2015, 152, $530-537$. [CrossRef]

39. Chen, H.; Hu, L.; Chen, M.; Yan, Y.; Wu, L. Nickel-cobalt layered double hydroxide nanosheets for high-performance supercapacitor electrode materials. Adv. Funct. Mater. 2014, 24, 934-942. [CrossRef]

40. Tao, Y.; Zaijun, L.; Ruiyi, L.; Qi, N.; Hui, K.; Yulian, N.; Junkang, L. Nickel-cobalt double hydroxides microspheres with hollow interior and hedgehog-like exterior structures for supercapacitors. J. Mater. Chem. 2012, 22, 23587-23592. [CrossRef]

41. Zhang, J.; Cheng, J.P.; Li, M.; Liu, L.; Liu, F.; Zhang, X.B. Flower-like nickel-cobalt binary hydroxides with high specific capacitance: Tuning the composition and asymmetric capacitor application. J. Electroanal. Chem. 2015, 743, 38-45. [CrossRef]

42. Yang, M.; Cheng, H.; Gu, Y.; Sun, Z.; Hu, J.; Cao, L.; Lv, F.; Li, M.; Wang, W.; Wang, Z.; et al. Facile electrodeposition of 3D concentration-gradient Ni-Co hydroxide nanostructures on nickel foam as high performance electrodes for asymmetric supercapacitors. Nano Res. 2015, 8, 2744-2754. [CrossRef]

43. Lu, P.; Halvorsen, E.; Ohlckers, P.; Müller, L.; Leopold, S.; Hoffmann, M.; Grigoras, K.; Ahopelto, J.; Prunnila, M.; Chen, X. Ternary composite $\mathrm{Si} / \mathrm{TiN} / \mathrm{MnO}_{2}$ taper nanorod array for on-chip supercapacitor. Electrochim. Acta 2017, 248, 397-408. [CrossRef]

44. Sun, X.; Wang, G.; Sun, H.; Lu, F.; Yu, M.; Lian, J. Morphology controlled high performance supercapacitor behaviour of the Ni-Co binary hydroxide system. J. Power Sources 2013, 238, 150-156. [CrossRef]

45. Gao, H.; Wang, G.; Yang, M.; Tan, L.; Yu, J. Novel tunable hierarchical Ni-Co hydroxide and oxide assembled from two-wheeled units. Nanotechnology 2011, 23, 015607. [CrossRef] [PubMed]

46. Wang, G.; Zhang, L.; Kim, J.; Zhang, J. Nickel and cobalt oxide composite as a possible electrode material for electrochemical supercapacitors. J. Power Sources 2012, 217, 554-561. [CrossRef]

47. Sun, Y.; Chen, L.; Wang, Y.; Zhao, Z.; Li, P.; Zhang, W.; Wang, Y.L.; Hu, J. Synthesis of $\mathrm{MoO}_{3} / \mathrm{WO}_{3}$ composite nanostructures for highly sensitive ethanol and acetone detection. J. Mater. Sci. 2017, 52, 1561-1572. [CrossRef] 
48. Pu, J.; Tong, Y.; Wang, S.; Sheng, E.; Wang, Z. Nickel-cobalt hydroxide nanosheets arrays on Ni foam for pseudocapacitor applications. J. Power Sources 2014, 250, 250-256. [CrossRef]

49. Liu, F.; Chu, X.; Zhang, H.; Zhang, B.; Su, H.; Jin, L.; Wang, Z.; Huang, H.; Yang, W. Synthesis of self-assembly 3D porous $\mathrm{Ni}(\mathrm{OH})_{2}$ with high capacitance for hybrid supercapacitors. Electrochim. Acta 2018, 269, 102-110. [CrossRef]

50. Xue, T.; Wang, X.; Lee, J.M. Dual-template synthesis of $\mathrm{Co}(\mathrm{OH})_{2}$ with mesoporous nanowire structure and its application in supercapacitor. J. Power Sources 2012, 201, 382-386. [CrossRef]

51. Roy, A.; Jadhav, H.S.; Thorat, G.M.; Seo, J.G. Electrochemical growth of $\mathrm{Co}(\mathrm{OH})_{2}$ nanoflakes on Ni foam for methanol electro-oxidation. New J. Chem. 2017, 41, 9546-9553. [CrossRef]

52. Jiang, C.; Zhao, B.; Cheng, J.; Li, J.; Zhang, H.; Tang, Z.; Yang, J. Hydrothermal synthesis of $\mathrm{Ni}(\mathrm{OH})_{2}$ nanoflakes on 3D graphene foam for high-performance supercapacitors. Electrochim. Acta 2015, 173, $399-407$. [CrossRef]

53. Jing, M.; Hou, H.; Banks, C.E.; Yang, Y.; Zhang, Y.; Ji, X. Alternating voltage introduced NiCo double hydroxide layered nanoflakes for an asymmetric supercapacitor. ACS Appl. Mater. Interfaces 2015, 7, 22741-22744. [CrossRef] [PubMed]

54. Wang, T.; Zhang, S.; Yan, X.; Lyu, M.; Wang, L.; Bell, J.; Wang, H. 2-Methylimidazole-derived Ni-Co layered double hydroxide nanosheets as high rate capability and high energy density storage material in hybrid supercapacitors. ACS Appl. Mater. Interfaces 2017, 9, 15510-15524. [CrossRef]

55. Fan, X.; Sun, Y.; Ohlckers, P.; Chen, X. Porous Thin-Wall Hollow $\mathrm{Co}_{3} \mathrm{O}_{4}$ Spheres for Supercapacitors with High Rate Capability. Appl. Sci. 2019, 9, 4672. [CrossRef]

56. Wu, J.; Mi, R.; Li, S.; Guo, P.; Mei, J.; Liu, H.; Lau, W.M.; Liu, L.M. Hierarchical three-dimensional $\mathrm{NiCo}_{2} \mathrm{O}_{4}$ nanoneedle arrays supported on $\mathrm{Ni}$ foam for high-performance supercapacitors. RSC Adv. 2015, 5, 25304-25311. [CrossRef]

57. Fan, X.; Ohlckers, P.; Chen, X. Tunable Synthesis of Hollow $\mathrm{Co}_{3} \mathrm{O}_{4}$ Nanoboxes and Their Application in Supercapacitors. Appl. Sci. 2020, 10, 1208. [CrossRef]

58. Cheng, Y.; Zhang, H.; Varanasi, C.V.; Liu, J. Improving the performance of cobalt-nickel hydroxide-based self-supporting electrodes for supercapacitors using accumulative approaches. Energy Environ. Sci. 2013, 6, 3314-3321. [CrossRef]

59. Hu, Z.A.; Xie, Y.L.; Wang, Y.X.; Wu, H.Y.; Yang, Y.Y.; Zhang, Z.Y. Synthesis and electrochemical characterization of mesoporous $\mathrm{Co}_{x} \mathrm{Ni}_{1-x}$ layered double hydroxides as electrode materials for supercapacitors. Electrochim. Acta 2009, 54, 2737-2741. [CrossRef]

60. Xie, L.; Hu, Z.; Lv, C.; Sun, G.; Wang, J.; Li, Y.; He, H.; Wang, J.; Li, K. CoxNii-x double hydroxide nanoparticles with ultrahigh specific capacitances as supercapacitor electrode materials. Electrochim. Acta 2012, 78, $205-211$. [CrossRef]

61. Liu, Y.; Fu, N.; Zhang, G.; Xu, M.; Lu, W.; Zhou, L.; Huang, H. Design of Hierarchical Ni-Co@Ni-Co Layered Double Hydroxide Core-Shell Structured Nanotube Array for High-Performance Flexible All-Solid-State Battery-Type Supercapacitors. Adv. Funct. Mater. 2017, 27, 1605307. [CrossRef]

62. Wang, Q.; Wang, X.; Liu, B.; Yu, G.; Hou, X.; Chen, D.; Shen, G. $\mathrm{NiCo}_{2} \mathrm{O}_{4}$ nanowire arrays supported on Ni foam for high-performance flexible all-solid-state supercapacitors. J. Mater. Chem. A 2013, 1, $2468-2473$. [CrossRef]

63. Wang, Y.; Lei, Y.; Li, J.; Gu, L.; Yuan, H.; Xiao, D. Synthesis of 3D-nanonet hollow structured $\mathrm{Co}_{3} \mathrm{O}_{4}$ for high capacity supercapacitor. ACS Appl. Mater. Interfaces 2014, 6, 6739-6747. [CrossRef] [PubMed]

64. Tang, Y.; Liu, Y.; Yu, S.; Guo, W.; Mu, S.; Wang, H.; Zhao, Y.; Hou, L.; Fan, Y.; Gao, F. Template-free hydrothermal synthesis of nickel cobalt hydroxide nanoflowers with high performance for asymmetric supercapacitor. Electrochim. Acta 2015, 161, 279-289. [CrossRef]

65. Lu, P.; Ohlckers, P.; Müller, L.; Leopold, S.; Hoffmann, M.; Grigoras, K.; Ahopelto, J.; Prunnila, M.; Chen, $X$. Nano fabricated silicon nanorod array with titanium nitride coating for on-chip supercapacitors. Electrochem. Commun. 2016, 70, 51-55. [CrossRef]

66. Bai, X.; Liu, Q.; Zhang, H.; Liu, J.; Li, Z.; Jing, X.; Yuan, Y.; Liu, L.; Wang, J. Nickel-cobalt layered double hydroxide nanowires on three dimensional graphene nickel foam for high performance asymmetric supercapacitors. Electrochim. Acta 2016, 215, 492-499. [CrossRef] 
67. Le, K.; Wang, Z.; Wang, F.; Wang, Q.; Shao, Q.; Murugadoss, V.; Wu, S.; Liu, W.; Liu, J.; Gao, Q.; et al. Sandwich-like NiCo layered double hydroxide/reduced graphene oxide nanocomposite cathodes for high energy density asymmetric supercapacitors. Dalton Trans. 2019, 48, 5193-5202. [CrossRef]

68. Cai, X.; Shen, X.; Ma, L.; Ji, Z.; Xu, C.; Yuan, A. Solvothermal synthesis of NiCo-layered double hydroxide nanosheets decorated on RGO sheets for high performance supercapacitor. Chem. Eng. J. 2015, 268, 251-259. [CrossRef]

(C) 2020 by the authors. Licensee MDPI, Basel, Switzerland. This article is an open access article distributed under the terms and conditions of the Creative Commons Attribution (CC BY) license (http://creativecommons.org/licenses/by/4.0/). 